Gut, 1987, 28, 210-215

\title{
Clinical markers of slow healing and relapsing gastric ulcer
}

\author{
G BATTAGLIA, F Di MARIO, A PICCOLI, F VIANELLO, F FARINATI, \\ AND R NACCARATO
}

From the Istituto di Medicina Interna, Cattedra Malattie Apparato Digerente, Policlinico Universitario, Padova, Italy

SUMMARY The aim of the study was to identify the clinical markers useful in characterising slow healing and relapsing gastric ulcer patients. Ninety nine subjects entered the short term and 79 the long term study (12 months). The following parameters were taken into account: therapy, sex, age, smoking habit, alcohol consumption, analgesic intake, peptic ulcer family history and onset of the disease. Results of the studies were analysed by means of $\chi^{2}$ test and logistic regression, both in stepwise and in specifying models. Cigarette smoking was found to be the most important risk factor of non-healing $(\mathrm{p}=0 \cdot 04)$. In women with late onset of the disease, cigarette smoking identified the gastric ulcer subjects at higher risk of non-healing with a predictive probability of $0 \cdot 4679$. Age under 50 years was found to be the most important risk factor of relapsing throughout the entire 12 month follow up period $(p=0.025)$. In those under 50 years, cigarette smoking and negative peptic ulcer family history in combination, identified the gastric ulcer subjects at higher risk of relapsing, the predicted probability being $0 \cdot 6027$. It is concluded that cigarette smoking is the most important risk factor for non-healing and those who relapse under the age of 50. The possibility of singling out categories of patients more prone not to heal and to relapse suggests new strategies in the management of gastric ulcer disease.

Despite the introduction in routine therapy of active antisecretory drugs (cimetidine, ranitidine, pirenzepine), nine to $25 \%$ of gastric ulcer patients do not heal after six to eight weeks full dose treatment. ${ }^{1-11}$ Conflicting (but substantially negative) results have been reported on the importance of various factors in influencing gastric ulcer healing: age, sex, analgesic intake, cigarette smoking, ulcer size and site, alcohol consumption, duration of the disease, were all found not to be really important in singling out gastric ulcer subjects more prone not to heal. ${ }^{4671013-19}$ More recently, in 75 hospitalised patients, Okada et $a^{20}$ found that age ( $>50$ years), ethanol intake ( $>60 \mathrm{~g} /$ daily), pain lasting more than three days, single ulcer and ulcer of the lesser curvature represent useful factors in characterising

Address for correspondence: Dr G Battaglia, Institute of Internal Medicine, Cattedra Malattie Apparato Digerente, Via Giustiniani 2, Padova, Italy.

Received for publication 13 June 1986. subjects more prone not to heal, the risk being higher in patients presenting two or more of these markers.

Fewer data are available as yet on the long term follow up of gastric ulcer. H2-blockers are effective in maintaining gastric ulcer remission, although eight to $21 \%$ of patients have an endoscopically documentable recurrence of the disease within the first 12 months of follow up. ${ }^{61121-25}$ Cigarette smoking has been reported as not influencing gastric ulcer outcome. ${ }^{4111^{1725-28}}$ Old age, size of ulcer and analgesic intake have been found by Piper $e t$ al in a four year study to be the major factors involved in ulcer relapse ${ }^{27}$ these data have not been confirmed by others. ${ }^{414} 17225$ Duration of ulcer disease and a past history of gastric ulcer were found recently to predispose patients to ulcer recurrence. ${ }^{25}$

Predictors of duodenal ulcer slow healing and relapse have recently been under study, ${ }^{29}$ we singled out some biochemical and clinical 'risk factors' of duodenal ulcer relapse. ${ }^{30}{ }^{31}$ In an attempt to ascertain 
whether simple clinical parameters are useful in identifying slow healing and relapsing subjects, we analysed the results of a short and long term (one year) study in a large gastric ulcer sample.

\section{Methods}

PATIENTS

Ninety nine consecutive patients ( 63 men, 36 women, mean age 53 years, range 27-82) with an endoscopically and histologically proven benign active gastric ulcer were retrospectively studied.

The Figure illustrates the protocol of the study. The patients had openly received either $1000 \mathrm{mg}$ cimetidine (69 patients), $300 \mathrm{mg}$ ranitidine (16 patients), $100 \mathrm{mg}$ pirenzepine (five patients) or other drugs such as sulglicotide $(150 \mathrm{mg})$, trithiozine $(1.2 \mathrm{~g})$, oxmetidine ( $800 \mathrm{mg}$ ) (nine patients) daily.

Eighty patients ( 54 men, 26 women, mean age 50 years, range 23-78) underwent an upper gastrointestinal endoscopy at $42 \pm 2 \cdot 3$ days (mean $\pm S D$ ), to assess healing. Nineteen subjects dropped out. The seventy nine patients who entered the 12 month follow up had endoscopic evidence of ulcer healing. Fifteen patients were left untreated apart from low dose antacids ( $\mathrm{Mg}$ - $\mathrm{Al}$ hydroxide) as required. The remaining 64 subjects were treated with the same drug used in the active phase, but in maintenance low dosages: either $400 \mathrm{mg}$ cimetidine (56 patients) or $150 \mathrm{mg}$ ranitidine (eight patients) at night. An upper gastrointestinal endoscopy was done at the third, sixth, and 12th month of follow up in all asymptomatic patients, and at every symptomatic relapse lasting more than three days. Three to 10 biopsies, either around the active lesion or on its scar, were taken at every endoscopy with the aim of excluding a gastric carcinoma. Patients had a clinical check up before each endoscopy.

Nine patients withdrew at the third, six at the sixth and two at the 12th month of follow up because they failed to attend the endoscopic examination. Therefore, 62 patients $(41$ men, 21 women, mean age 51 years, range 27-70) completed the long term study (Table 1).
The following parameters were considered in order to assess the most important in influencing either the healing of the lesion or its recurrence throughout the 12 month follow up: therapy, sex, age (under or over 50), smoking habit (less or more than 10 cigarettes daily - that is, mild or non-smokers $v s$ heavy smokers, alcohol consumption (less or more than $60 \mathrm{~g}$ of ethanol intake daily - that is, mild or nondrinkers $v s$ heavy drinkers), analgesic intake, family history of peptic ulcer, early onset of the disease (before the third decade of life). The cimetidine treated patients were also considered separately as a further control group to exclude any bias caused by the treatment carried out.

\section{STATISTICAL ANALYSIS}

Chi-squared test was first used to compare the various treatment groups, then statistical analysis was done through logistic regression, both in stepwise and by specifying models using the program of the B MDP statistical package. ${ }^{32}$

Through stepwise logistic regression, the proportion of failures (unhealing, relapse) can be predicted by the logistic model: $\exp (U) /(1+\exp (U))$, where $U$ is a linear combination of independent variables (predictors) chosen in a stepwise fashion - that is, selected as the most useful variables. To verify important interactions among predictors, tentative models must be specified: a set of variables which are assumed to interact. In the present work all predictors were simplified as either categorical or binary. Once a good model is found to fit the proportion of failures, the probability of failure of a new patient can be predicted, using the coefficients of the linear combination $U$ appended to the particular values of patient predictors. Coefficients indicate the relative importance of predictors in the model.

\section{Results}

No significant differences were detected among the treatment groups with the exception of 'early onset of the disease', which was significantly more frequent in the 'other drugs' group (Table 2).

Table 1 Gastric ulcer: assessment after long term follow up (12 months)

\begin{tabular}{|c|c|c|c|c|c|c|c|c|c|}
\hline \multirow{4}{*}{$\begin{array}{l}\text { Therapy carried out } \\
\text { Cimetidine } 400 \text { mg nocte }\end{array}$} & \multirow{4}{*}{$\begin{array}{l}\text { Total } \\
56\end{array}$} & \multicolumn{6}{|c|}{ Endoscopic controls } & \multirow{3}{*}{$\begin{array}{l}\text { Total } \\
\text { relapses }\end{array}$} & \multirow{3}{*}{$\begin{array}{l}\text { Total } \\
\text { drop outs }\end{array}$} \\
\hline & & \multicolumn{2}{|c|}{ 3rdmonth } & \multicolumn{2}{|c|}{ 6th month } & \multicolumn{2}{|c|}{12 th month } & & \\
\hline & & DO & $\mathbf{R}$ & DO & $\mathbf{R}$ & DO & $\mathbf{R}$ & & \\
\hline & & 5 & 3 & 4 & 9 & 2 & - & 12 & 11 \\
\hline Ranitidine 150 mg nocte & 8 & 3 & - & 1 & - & - & 1 & 1 & 4 \\
\hline None & 15 & 1 & 1 & 1 & - & - & 5 & 6 & 2 \\
\hline Total & 79 & 9 & 4 & 6 & 9 & 2 & 6 & 19 & 17 \\
\hline
\end{tabular}

$\mathrm{DO}=$ drop outs $; \mathrm{R}=$ relapses . 
99

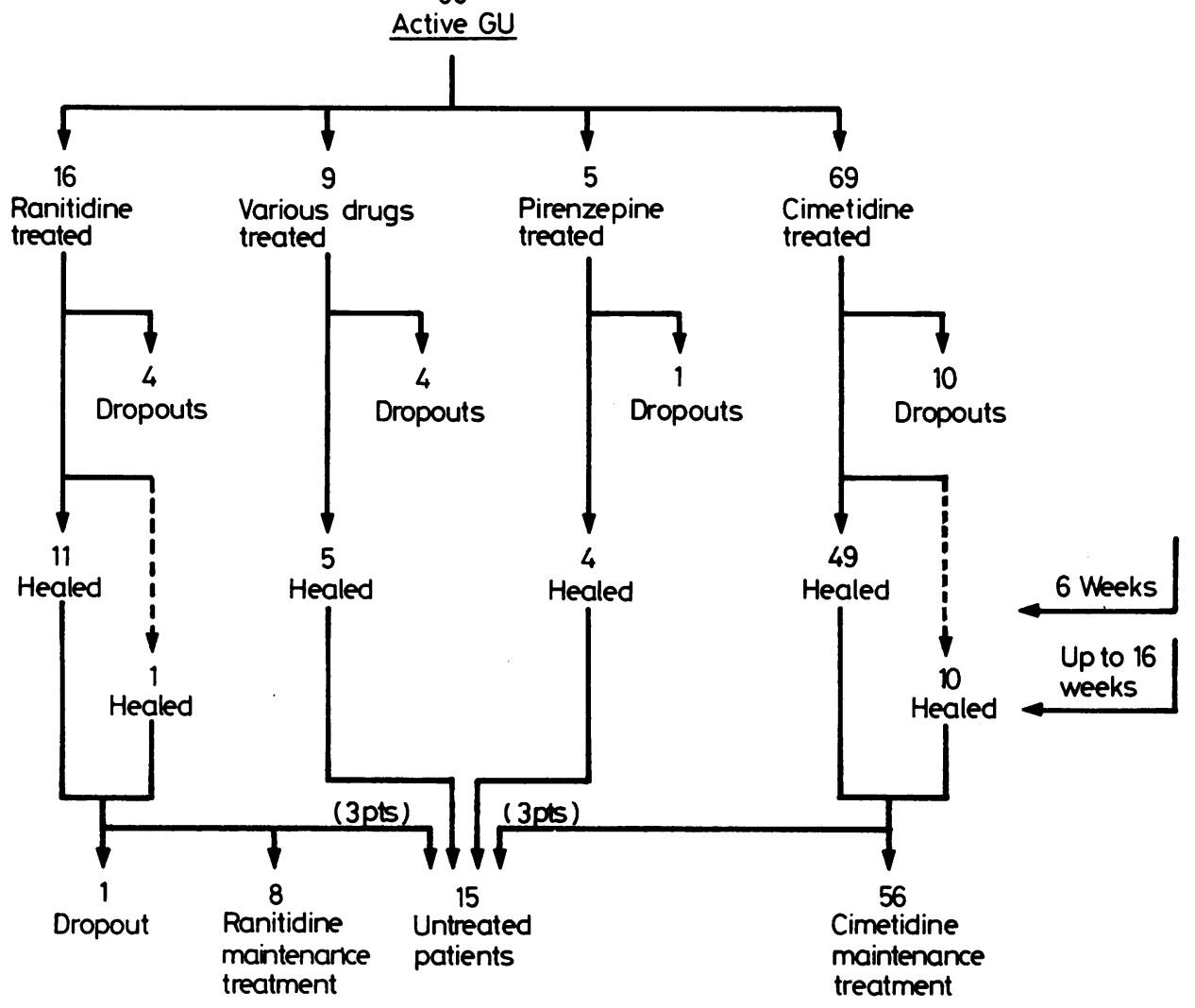

Figure. Protocol of the study.

Eleven out of the 80 gastric ulcer patients who completed the short term study $(13.75 \%)$ were found to be not healed at endoscopic examination. Logistic regression analysis shows that smoking habit, sex, and onset of the disease are the most important factors in singling out unhealed gastric ulcer subjects $(p=0 \cdot 04, p=0 \cdot 10, p=0 \cdot 16$, respectively). Only smoking habit had a $p$ value less than 0.05 . Table 3 shows the predicted probabilities of all possible combinations of values of variables in detecting unhealed gastric ulcer patients. In the cimetidine treated subgroup of patients the above reported results were largely confirmed, with the same parameters - that is, smoking habit, sex, and onset of the disease, being the most significant $(p=0.05$, $p=0 \cdot 12, p=0 \cdot 08$, respectively). The predicted nonhealing probability of a cimetidine treated female heavy smoker with a late onset of the disease was found to be $p=0.5435$.

Nineteen out of the 62 gastric ulcer patients who completed the long term study $(30.6 \%)$ relapsed at some time in the observation period (Table 1).
Logistic regression analysis showed that age, smoking habit, and peptic ulcer family history are the most important factors in singling out relapsing gastric ulcer subjects $(p=0.025, p=0.11, p=0.16$, respectively). Only age had a $p$ value less than 0.05 . Table 4 shows the predicted probabilities of all possible combinations of values of variables in singling out relapsing patients. In the H2-blocker treated group of patients, the above reported results were partially confirmed with the same parameters that is, age and peptic ulcer family history, being the most significant $(p=0.05, p=0.08$, respectively). Smoking habit did not reach statistical significance in this group. The predicted relapsing probability of an H2-blocker treated patient with a negative peptic ulcer family history and an age under 50 years was found to be $p=0 \cdot 5165$.

\section{Discussion}

Cigarette smoking is reported to be the most important exogenous factor characterising duodenal 
Table 2 Clinical details and treatment of gastric ulcer patients who completed the short term and long term study

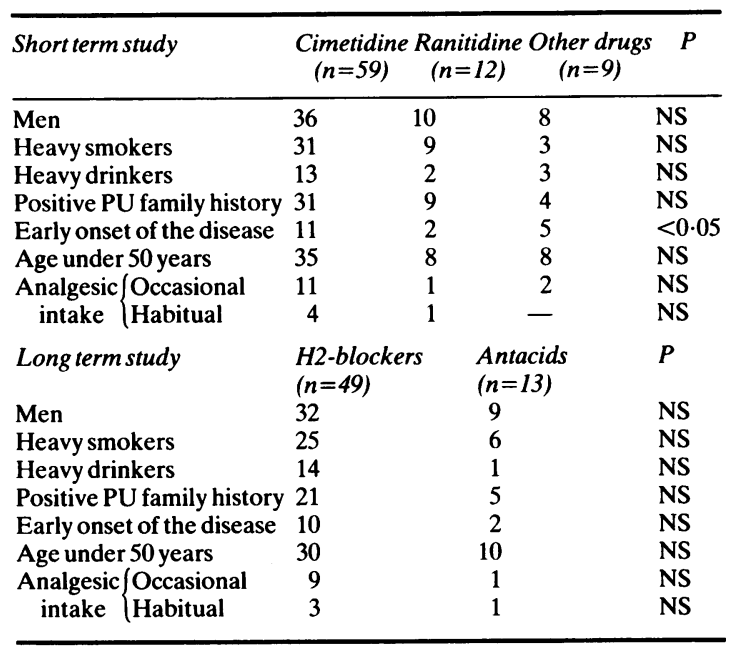

Table 3 All possible combinations of values of variables in the model and the predictive probability of unhealing

\begin{tabular}{llll}
\hline Sex & Smoking habit & Onset of the disease & $\begin{array}{l}\text { Predicted } \\
\text { probability }\end{array}$ \\
\hline F & $<10$ & III & 0.1996 \\
M & $<10$ & III & 0.0367 \\
M & $<10$ & III & 0.0119 \\
F & $<10$ & III & 0.0731 \\
M & $>10$ & III & 0.1185 \\
M & $>10$ & III & 0.2983 \\
F & $>10$ & $>$ III & 0.4679 \\
\hline
\end{tabular}

*Predicted probability ranges between 0 (absence of the event) and 1 (presence of the event); $M=$ Male; $F=$ Female; $<10=$ less than 10 cigarettes daily; $>10=$ more than 10 cigarettes daily; $<\mathrm{III}=$ before third decade of life; $>$ III = after third decade of life.

ulcer patients with a poorer clinical outcome; both slow healing ${ }^{32-35}$ and relapse $e^{293135-37}$ are closely connected with heavy smoking.

The results in literature of the effect of cigarette smoking on gastric ulcer outcome are conflicting: some authors report no influence 4610161720 and Leroux et al surprisingly found a positive effect.' Our data are in agreement with that of Doll, ${ }^{13}$ who reports a significantly negative influence. Other clinical parameters - that is, female sex and late onset of the disease, were also found to be important, though less so statistically. These results are substantially in disagreement with the few that have appeared in the literature..$^{471020}$ In accordance with the more recent literature,${ }^{911}$ full dose cimetidine and ranitidine seem to be equally effective in promoting gastric ulcer healing.

As regards long term follow up, absence of peptic
Table 4 All possible combinations of values of variables in the model and the predicted probability of relapsing

\begin{tabular}{llll}
\hline Smokinghabit & PUfamily history & Age & $\begin{array}{l}\text { Predicted } \\
\text { probability }\end{array}$ \\
\hline$<10$ & YES & $>50$ & $0 \cdot 0483$ \\
$>10$ & YES & $>50$ & $0 \cdot 1108$ \\
$>10$ & NO & $>50$ & $0 \cdot 2301$ \\
$<10$ & NO & $>50$ & $0 \cdot 1085$ \\
$<10$ & YES & $<50$ & $0 \cdot 2048$ \\
$<10$ & NO & $<50$ & $0 \cdot 3820$ \\
$>10$ & YES & $<50$ & $0 \cdot 3874$ \\
$>10$ & NO & $<50$ & $0 \cdot 6027$
\end{tabular}

*Predicted probability ranges between 0 (absence of the event) and 1 (presence of the event) $;<10=$ less than 10 cigarettes daily;

$>10=$ more than 10 cigarettes daily.

ulcer family history, cigarette smoking and, mainly, age under 50 years, characterised our gastric ulcer patients with a higher risk of relapse. These results are in disagreement with the observations of many authors, who have found that gastric ulcer relapse is influenced neither by cigarette smoking ${ }^{411} 172126-28$ nor by age. ${ }^{472126}$ Unlike Piper, ${ }^{27}$ we found that gastric ulcer subjects under 50 years have a significantly higher risk of relapse. This might be accounted for by the inverse correlation between age and gastric acid secretion $^{38}$ or greater stress generally linked to work. Therapy did not significantly influence outcome: $50 \%$ of untreated as opposed to $26 \%$ of treated patients relapsed $(0 \cdot 05>\mathrm{p}<0 \cdot 10)$. This may be explained by the small sample of untreated subjects and unequal composition of the three groups. Our findings in the entire gastric ulcer population, however, were substantially confirmed by those in the more homogeneous group of $\mathrm{H} 2$-blocker treated subjects.

As far as we are aware, the present study constitutes the first attempt at specifically detecting predictive markers of both slow healing and relapsing gastric ulcer. Our results show that: (1) cigarette smoking is the most important risk factor of gastric ulcer non-healing; (2) relatively young age (under 50 years) significantly characterises relapsing subjects. The statistical method we used was able to predict the non healing- and relapsing risk for each of the possible combinations of values of the most useful variables: acquired (eliminable) factors - that is, cigarette smoking, on the one hand, and genetic factors - that is, female sex, late onset of the disease, negative peptic ulcer family history and young age, on the other, were together able to identify gastric ulcer patients with a risk of poorer outcome.

It remains to be established whether stopping smoking and a different therapeutic approach to 'high risk subjects' may increase the gastric ulcer healing and remission rate. 
This study was conducted under the auspices of the Roberto Farini Foundation and for Gastroenterological Research, and partially supported by a grant for the Ministero Pubblica Istruzione, Project 83.02119.04.

We should like to thank Ms Margherita Ulrych for her linguistic help in preparing the manuscript.

\section{References}

1 Ciclitira PJ, Machell RJ, Farthing MJ, Dick AP, Hunter J. A controlled trial of cimetidine in the treatment of gastric ulcer. In: Burland WL, Simkins MA, eds. Cimetidine. Amsterdam: Excerpta Medica, 1977: 283-6.

2 Dyck WP, Belsito A, Flesher B, Lieberman TR, Dickinson PB, Wood JM. Cimetidine and placebo in the treatment of benign gastric ulcer. A multicenter doubleblind study. Gastroenterology 1978; 74: 410-5.

3 Navert HL, Larose R, Beaudry L, et al. Cimetidine is effective in the treatment of gastric ulcer. Gastroenterology 1978; 74: 1072.

4 Gwyn Morgan A, McAdam WAF, Pacsoo C, Walker BE, Simmons AV. Cimetidine: an advance in gastric ulcer treatment? Br Med J 1978; 2: 1323-6.

5 Gibinsky K, Nowak A, Gabryelewicz A, et al. Multicenter double-blind clinical trial on ranitidine for gastroduodenal ulcer. Hepato-Gastroenterol 1981; 28: 216-7.

6 Gwyn Morgan A, McAdam WAF, Pacsoo C, Darnborough $\mathrm{A}$. Comparison between cimetidine and Caved-S in the treatment of gastric ulceration, and subsequent maintenance therapy. Gut 1982; 23: 545-51.

7 Leroux P, Farley A, Archambault A, et al. Effect of ranitidine on healing of peptic ulcer: a 2-month study. Am J Gastroenterol 1983; 78: 227-30.

8 Isenberg JI, Peterson WL, Elashoff JD, et al. Healing of benign gastric ulcer with low-dose antacid or cimetidine. A double-blind randomized, placebo-controlled trial. N Engl J Med 1983; 308: 1319-24.

9 Barbara L, Corinaldesi R, Dobrilla G, et al. Ranitidine vs cimetidine: short-term treatment of gastric ulcer. Hepato-Gastroenterol 1983; 30: 151-3.

10 The Belgian Peptic Ulcer Study Group. Single blind comparative study of ranitidine and cimetidine in patients with gastric ulcer. Gut 1984; 25 : 999-1002.

11 Dawson J, Jain S, Cockel R. Effect of ranitidine and cimetidine on gastric ulcer healing and recurrence. Scand J Gastroenterol 1984; 19: 665-8.

13 Doll R, Jones, AF, Pygott F. Effect of smoking on the production and maintenance of gastric and duodenal ulcers. Lancet 1958; i: 657-66.

14 The Veterans Administration Cooperative Study on Gastric Ulcer. Gastroenterology 1971; 61: 567-654.

15 Hermann RP, Piper DW. Factors influencing the healing rate of chronic gastric ulcer. Am J Dig Dis 1973; 18: $1-6$.

16 Kellow JE, Barr GD, Cowen AE, Ward M, Wood L,
Piper DW. Comparison of ranitidine and cimetidine in the treatment of chronic gastric ulcer. Digestion 1983; 27: 105-10.

17 Sutton DR. Gastric ulcer healing with tripotassium dicitrato bismuthate and subsequent relapse. Gut 1982; 23: 621-4.

18 Piper DW, Hunt J, Heap TR. The healing rate of chronic gastric ulcer in patients admitted to hospital. Scand J Gastroenterol 1980; 15: 113-7.

19 Nakajima T. Studies on factors affecting healing of gastric ulcer. A prospective, cooperative study in Japan. Am J Gastroenterol 1976; 66: 150-4.

20 Okada M, Yao T, Fuchigami T, Imamura K, Omae T. Factors influencing the healing rate of gastric ulcer in hospitalized subjects. Gut 1984; 25: 881-5.

21 Barr GD, Kang JY, Canalese J, Piper DW. A two-year prospective controlled study of maintenance cimetidine and gastric ulcer. Gastroenterology 1983; 85: 100-4.

22 Birger Jensen K, Mollmann KM, Rahbek I, Rask Madsen J, Rune SJ, Wulff HR. Prophylactic effect of cimetidine in gastric ulcer patients. Scand J Gastroenterol 1979; 14: 175-6.

23 Machel RJ, Farthing MJC, Ciclitira PJ, Dick AP, Hunter JO. Cimetidine in the prevention of gastric ulcer relapse. Postgrad Med J 1979; 55: 393-5.

24 Hentschel E, Schütze A, Weiss W, et al. Effect of cimetidine treatment in the prevention of gastric ulcer relapse: a one-year double-blind multicentre study. Gut 1983; 24: 853-6.

25 Morgan AG, Pacsoo C, McAdam WAF. Maintenance therapy: a two-year comparison between Caved-S and cimetidine in the prevention of symptomatic gastric ulcer recurrence. Gut 1985; 26: 599-602.

26 Piper DW, Greig M, Coupland GAE, Hobbin E, Shinners J. Factors relevant to the prognosis of chronic gastric ulcer. Gut 1975; 16: 714-8.

27 Piper DW, Shinners J, Greig M, Thomas J, Waller SL. Effect of ulcer healing on the prognosis of chronic gastric ulcer. Gut 1978; 19: 419-24.

28 Classen M, Bethge H, Brunner G, et al. Effect of sucralfate on peptic ulcer recurrence: a controlled double-blind multicentre study. Scand J Gastroenterol 1983; 18: suppl. 83: 61-8.

29 Sonnenberg A, Muller-Lissner SA, Vogel E, et al. Predictors of duodenal ulcer healing and relapse. Gastroenterology 1981; 81: 1061-7.

30 Battaglia G, Farini R, Di Mario F,et al. Is maximal acid output useful in identifying relapsing duodenal ulcer patients? J Clin Gastroenterol 1985; 7: 375-8.

31 Battaglia G, Farini R, Di Mario F, et al. Recurrence of duodenal ulcer under continuous antisecretory treatment: an approach to the detection of predictive markers. Am J Gastroenterol 1984; 79: 831-4.

32 Engelman L. Stepwise logistic regression. In: Dixon WJ, Brown MB, Engelman L, et al, eds. BMDP statistical software. Berkeley: UCLA, 1981: 330-42.

33 Gugler R, Rohner HG, Kratochvil P, Branstatter G, Schmitz $\mathbf{H}$. Effect of smoking on duodenal ulcer healing with cimetidine and ranitidine. Gut 1982; 23: 866-71.

34 Korman HG, Hansky J, Merrett AC, Schmidt GT. Ranitidine in duodenal ulcer: incidence of healing and effect of smoking. Dig Dis Sci 1982; 27: 712-5. 
35 Korman HG, Hansky J, Eaves ER, Schmidt GT. Influence of cigarette smoking on healing and relapse in duodenal ulcer disease. Gastroenterology 1983; 85: 871-4.

36 Ippoliti A, Elashoff J, Valenzuela J, et al. Recurrent ulcer after successful treatment with cimetidine or antacid. Gastroenterology 1983; 85: 875-80.
37 Sontag S, Graham DY, Belsito A, et al. Cimetidine, cigarette smoking and recurrence of duodenal ulcer. N Engl J Med 1984; 311: 689-93.

38 Baron JH. Gastric secretion tests. (10) Biological factors. In: Clinical tests of gastric secretion. History, methodology and interpretation. London: Macmillan Press, 1978: 56-65. 